\title{
Effectiveness of antismoking drug treatment in patients with psychiatric comorbidity compared with patients without this comorbidity
}

\author{
Raul G. Mayoral', F. J. González', Javier C. Ruiz', Marta G. Crespo', Ana T. \\ Molina ${ }^{1}$, Pedro J. Tárraga López, Jose A. R. Montes ${ }^{4}$ \\ ${ }^{1}$ Pneumology Department, ${ }^{2}$ Thoracic Surgery Department, Albacete University Hospital \\ Complex (CHUA), Albacete, Spain \\ ${ }^{3}$ Family and Community Medicine Department, Albacete Integrated Care Management (GAI), \\ Albacete,Spain \\ ${ }^{4}$ General and Gastrointestinal Surgery Department, La Paz University Hospital, Madrid, Spain
}

\begin{abstract}
Background: There is a relationship between smoking and some psychiatric disorders, and there is doubt whether antismoking treatment will be more complex because of psychiatric disorder.

Aim: To analyze the differences in treatment success rates among patients without psychiatric disorder and patients with psychiatric disorder who have received complete pharmacological treatment.

Materials and Methods: A retrospective cohort study was conducted using the records of patients completely treated at Albacete University Hospital Complex during 2011. The sample comprised 293 patients seen in 2011. We treated only 73 patients and divided them into patients with or without psychiatric disorders. We analyzed the following variables: sex, age, age at smoking onset, previous quitting attempts, cigarettes per day, CO-oximetry, Fagerström test, Richmond test, alcoholism, treatment distribution, treatment failure, success, and relapse.

Results: Of a total sample of 293 patients seen in 2011, 73 patients were treated: 43 were men and 30 were women. Overall, 37\% had psychiatric disorder (five men and 22 women). Treatment was successful in $51(70 \%)$ patients. There were no differences between the demographic characteristics of the two groups, except for sex $(P<0.05)$; or regarding success, failure, or relapse; or regarding success analyzed separately according to sex distribution.

Conclusion: Smoking cessation treatment is equally effective in patients with and without psychiatric disorders. The characteristics of the patients with psychiatric disorders who completed the pharmacological treatment did not differ in intensity, motivation, or dependence from those with no psychiatric comorbidity. Smoking women have more psychiatric morbidity; however, the treatment is effective.
\end{abstract}

Received: 29 December 2016, Accepted: 09 December 2017

Key Words: Bupropion, failure, nicotine replacement therapy, psychiatric comorbidity, relapse, smoking, smoking cessation, treatment success, varenicline

Corresponding Author: Pedro J. Tarraga Lopez, M.D., Pneumology Department, Albacete University Hospital Complex (CHUA), Albacete, Spain, Tel.: 967505263, E-mail: pjtarraga@sescam.jccm.es

ISSN: 0013-2446, Vol. 92, No.2

\section{INTRODUCTION}

Smoking is the single most important cause of preventable and avoidable morbidity and premature mortality in developed countries ${ }^{[1]}$. Multiple diseases of all kinds (neoplasms, infections, and inflammatory diseases, among others) are directly caused or related to exposure to tobacco ${ }^{[2]}$.

Smoking is a systemic disease that was included in the 2015 version of the International Statistical Classification of Diseases 10 and health related problems, in section F17-Mental and behavioural disorders due to use of tobacco ${ }^{[3-5]}$. It is classified under 'Mental and behavioral disorders due to psychoactive substance use' and is cataloged by the Diagnostic and Statistical Manual of Mental Disorders, fifth ed., ${ }^{[6]}$ of the American Psychiatric Association.

As early as 1986, a strong relation between tobacco and psychiatric symptomatology was corroborated ${ }^{[7]}$, featuring a proportional relationship between the intensity of the symptoms and tobacco dependence ${ }^{[8]}$.

There have been effective treatments that have proven to be cost effective, with the combination of psychological support and pharmacological therapy being the most effective one ${ }^{[9,10]}$. Pharmacological treatment should be 
offered to any smoker who seriously wants to attempt smoking cessation, unless there are contraindications.

There are several therapeutic alternatives for the treatment of smoking patients: (a) nicotine replacement therapy (NRT) ${ }^{[11]}$, which entails attempts to give nicotine doses via other route to decrease withdrawal symptoms. The regimen is $8-12$ weeks. (b) Bupropion ${ }^{[12]}$ : it is the first non-nicotinic drug approved for smoking treatment. It is an antidepressant that acts as a dopamine and noradrenaline reuptake inhibitor, and is also a noncompetitive nicotine receptor antagonist. The treatment duration is between 7 and 9 weeks. (c) Varenicline ${ }^{[13]}$ : it is a partial $\alpha 4 \beta 2$ nicotinic receptor agonist. The recommended initial treatment duration is 12 weeks.

Patients with psychiatric disorders have higher smoking rates than the general population. In addition, it was presupposed that antismoking treatment will be more difficult in these patients owing to their psychiatric disorder ${ }^{[14]}$.

We aimed to determine whether there is a difference in the treatment success rate between general population and patients with psychiatric disorders who have received the complete pharmacological treatment and duration.

\section{MATERIALS AND METHODS}

A retrospective cohort study using records of patients treated at the Smoking Cessation Unit of Albacete University Hospital Complex was conducted during the period between 1 January 2011 and 31 December 2011, with a subsequent year of follow-up of those who had completed the pharmacological treatment.

The Smoking Cessation Unit receives patients from all over the province of Albacete. It was created in 2003 following the 'Smoking Treatment and Prevention Plan in Castilla-La Mancha 2003-2010' by SESCAM (Health Service of Castilla-La Mancha).

The follow-up of the patients in the Smoking Cessation Unit is systematized and protocolized:

In the first visit, both a general medical history and a specific smoking history, and a thorough physical examination were taken; moreover, the heart rate, blood pressure, anthropometric data (weight, height, and BMI), and CO-oximetry were measured. Nicotinic dependence was measured by the Fagerström test, and the motivation of the subject to face smoking cessation treatment was measured by the Richmond test.

Once the subject was confirmed to be a regular smoker, the first day of smoking cessation was marked and the next visit was scheduled. In this first visit, the pharmacological treatment was decided individually according to the number of cigarettes consumed per day, nicotine dependence test, CO-oximetry, comorbidity, contraindications, pharmacological interactions, and patient preferences. The pharmacological treatment that was usually proposed was
NRT, bupropion, or varenicline, or in exceptional cases, a combination of antismoking therapy. NRT is usually prescribed for 8-12 weeks, bupropion for $\sim 8$ weeks, and varenicline for $\sim 12$ weeks. When a patient had completed these treatment periods, he/she was included in the group of those who had received a complete pharmacological treatment.

During treatment follow-up, support for cognitivebehavioral therapy was provided. The successive visits were used to control symptoms of withdrawal, to perform CO-oximetry, and to assess vital and respiratory signs. Consultations were also done to solve problems, to enforce the correct compliance of the treatment, and to treat possible adverse effects.

Although pharmacological treatment lasted between 8 and 12 weeks, follow-up, psychological therapy, and support were maintained for 1 year.

Only patients who completed the prescribed pharmacological treatment were selected. This group of patients was divided into two groups: a group with psychiatric disorders and the other without.

\section{Statistical analysis}

The analysis was performed by the IBM SPSS Statistics 22.0 application (SSPS Inc., IBM, USA, Armonk, NY: IBM Corp.). Qualitative variables were summarized by using frequency and percentage, whereas measures of central tendency such as the mean and SD were used to measure dispersion for the quantitative variables. Comparisons were made to see the similarities and differences between the two groups, using $\chi^{2}$ and Fisher's exact for the quantitative variables and Student's t-test for the quantitative ones.

Success rates were analyzed by $\chi^{2}$-test. Success was defined as continuous and maintained smoking abstinence for 1 year. The failure variable included patients who were unable to maintain $24 \mathrm{~h}$ without smoking, and relapse was defined as the time in which the patient returned to smoking after a minimum abstinence period of $24 \mathrm{~h}$ and more than 1 year. An analysis according to sex distribution was also performed. The level of significance was set at $5 \%(P \leq 0.05)$.

\section{Ethical considerations}

Data were extracted from the database of patients with a smoking approach after being anonymized and approved by the Clinical Research Ethics Committee of our Area.

\section{RESULTS}

The total number of patients seen in 2011 was 293, of which, only 73 completed the pharmacological therapy. The group without psychiatric comorbidity included 46 patients (25 males and 19 females), with a mean age of 44.78 years (SD: 8.9 years), starting smoking for an average of 16.67 years (SD: 1.84), and had previously attempted smoking cessation 1.52 times (SD: 1.7), with an average consumption of 22.07 cigarettes per day 
(SD: 8.1). Basal mean CO-oximeter was 17.87 (SD: 9.26). The mean score for the Fagerström dependence test was 5.91 (SD: 2.1) and the Richmond motivation score was 8.35 (SD: 1.34). Among the patients, there were three alcoholics. As for the type of treatment, one patient did not receive pharmacological treatment, 10 NRT, 7 bupropion, 27 varenicline, and 1 patient received combined therapy (Table 1).

Table 1: Characteristics of patients in the sample, and comparison between those with or without psychiatric comorbidity, Albacete University Hospital Complex, Albacete, Spain, 2011

\begin{tabular}{|c|c|c|c|c|}
\hline Characteristics & $\begin{array}{l}\text { Total } 73 \\
{[\mathrm{n}(\%)]}\end{array}$ & $\begin{array}{c}\text { CoPsych } \\
(\mathrm{N}=27)[\mathrm{n}(\%)]\end{array}$ & $\begin{array}{c}\text { No CoPsych } \\
(\mathrm{N}=46)[\mathrm{n}(\%)]\end{array}$ & $P$ \\
\hline Men & $30(41.1)$ & $5(18.5)$ & $25(54.3)$ & 0.003 \\
\hline Women & $43(58.9)$ & $22(81.5)$ & $21(45.7)$ & \\
\hline Age & $46(9.43)$ & $48.08(10.12)$ & 44.78 (8.9) & 0.151 \\
\hline Onset age & $16.67(2.22)$ & $16.67(2.8)$ & $16.67(1.84)$ & 0.989 \\
\hline Previous attempts & $1.58(1.61)$ & $1.67(1.47)$ & $1.52(1.7)$ & 0.713 \\
\hline Cig/day & $22.07(8.85)$ & $22.07(10.15)$ & $22.07(8.11)$ & 0.997 \\
\hline CO-oximetry & $17.63(10.35)$ & $17.22(12.16)$ & $17.87(9.26)$ & 0.798 \\
\hline Fagerström & $5.85(2.39)$ & $5.74(2.9)$ & $5.91(2.1)$ & 0.769 \\
\hline Richmond & $8.44(1.25)$ & $8.59(1.08)$ & $8.35(1.34)$ & 0.422 \\
\hline CoPsych & $27(37)$ & $27(36)$ & $46(52)$ & \\
\hline Alcoholism & $8(11)$ & $5(18.5)$ & $3(6.6)$ & 0.102 \\
\hline \multicolumn{5}{|l|}{ Treatment type } \\
\hline No treatment & $2(2.7)$ & $1(3.7)$ & $1(2.2)$ & 0.57 \\
\hline NRT & $17(23.3)$ & $7(25.9)$ & $10(21.7)$ & \\
\hline BUP & $12(16.4)$ & $5(18.5)$ & $7(15.2)$ & \\
\hline VRN & $40(54.8)$ & $13(48.1)$ & $27(58.7)$ & \\
\hline Combined & $2(2.8)$ & $1(3.7)$ & (2.2) 1 & \\
\hline
\end{tabular}

BUP: bupropion, Cig: cigarettes, Combined: combination of treatments, CoPsych: psychiatric comorbidity, NRT: nicotine replacement therapy; VRN, varenicline

There were no significant differences between patients with psychiatric comorbidity (CoPsych) and patients without CoPsych in any of the aforementioned characteristics, except for sex $(P=0.003)$.

Overall, 34 patients without CoPsych and 17 with CoPsych succeeded to quit smoking, whereas three patients without CoPsych and one patient with CoPsych failed. As for relapses, of those who did not have CoPsych, five patients relapsed back to smoking during the first 3 months, two patients relapsed in the period between 3 and 6 months, and two patients in the period between 6 months and a year, whereas of those who did present CoPsych, there were six relapse cases in the first 3 months, two relapse cases in the period between 3 and 6 months, and one relapse case in the period between 6 months and a year. Neither in the success variable nor in relapses nor in failure were there significant differences (Table 2 and Fig. 1). 
Table 2: Results of treatment in patients with and without psychiatric comorbidity, Albacete University Hospital Complex, Albacete, Spain, 2011

\begin{tabular}{|c|c|c|c|c|}
\hline Results of treatment & Total $[\mathrm{n}(\%)]$ & CoPsych $[\mathrm{n}(\%)]$ & No CoPsych [n (\%)] & Test of significance $(\mathrm{P})$ \\
\hline Failure & $4(5.5)$ & $1(3.7)$ & $3(6.5)$ & 0.102 \\
\hline \multicolumn{5}{|l|}{ Relapse } \\
\hline 3 months & $11(15.1)$ & $6(22.2)$ & $5(10.9)$ & 0.6 \\
\hline 6 months & $4(5.5)$ & $2(7.4)$ & $2(4.3)$ & \\
\hline 1 year & $3(4.1)$ & $1(3.7)$ & $2(4.3)$ & \\
\hline Success & $51(69.1)$ & $17(63)$ & $34(73.9)$ & 0.32 \\
\hline
\end{tabular}

CoPsych, psychiatric comorbidity

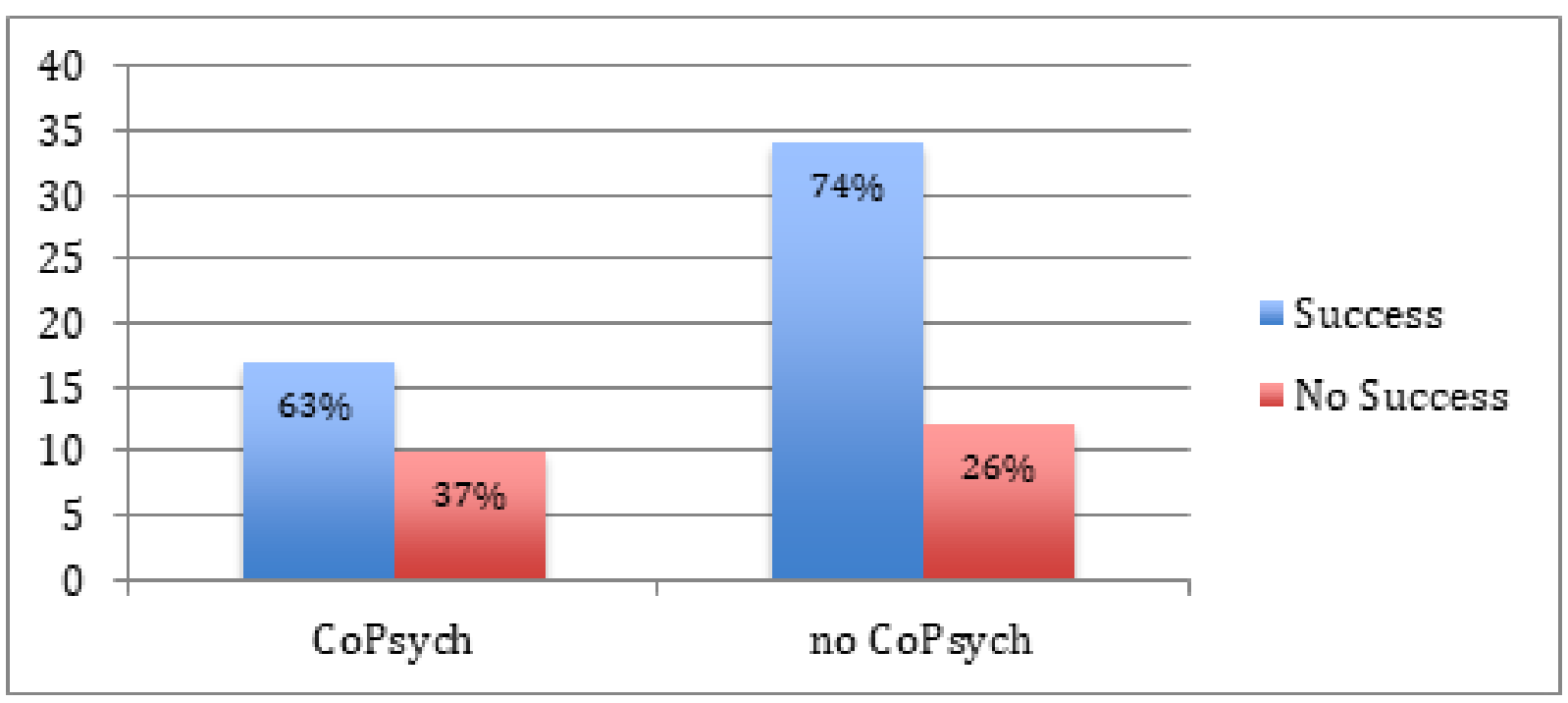

Fig.1: Relation between success and psychiatric comorbidity

The sample was distributed according to sex, and it was observed that among the men with CoPsych, three patients succeeded to quit smoking, whereas of those without CoPsych 18 patients succeeded, with no significant differences using the Fisher exact test. In women with CoPsych, 21 patients succeeded compared with 22 patients of those without CoPsych, without significant differences also (Table 3). 
Table 3: Success in patients with and without psychiatric comorbidity according to sex, Albacete University Hospital Complex, Albacete, Spain, 2011

\begin{tabular}{|c|c|c|c|c|}
\hline & \multicolumn{2}{|c|}{ Psychiatric comorbidity } & \multirow{2}{*}{ Total of patients } & \multirow{2}{*}{ Test of significance $(P)$} \\
\hline & No comorbidity & with & & \\
\hline \multicolumn{5}{|l|}{ Gender } \\
\hline \multicolumn{5}{|l|}{ Men } \\
\hline \multicolumn{5}{|l|}{ Success } \\
\hline No & 7 & 2 & 9 & 0.622 \\
\hline Yes & 18 & 3 & 21 & \\
\hline Total & 25 & 5 & 30 & \\
\hline \multicolumn{5}{|l|}{ Women } \\
\hline \multicolumn{5}{|l|}{ Success } \\
\hline No & 5 & 8 & 13 & 0.37 \\
\hline Yes & 16 & 14 & 30 & \\
\hline Total & 21 & 22 & 43 & \\
\hline \multicolumn{5}{|l|}{ Total } \\
\hline \multicolumn{5}{|l|}{ Success } \\
\hline No & 12 & 10 & 22 & 0.32 \\
\hline Yes & 34 & 17 & 51 & \\
\hline Total & 46 & 27 & 73 & \\
\hline
\end{tabular}

\section{DISCUSSION}

There is a strong relation between tobacco and psychiatric symptomatology ${ }^{[7]}$, featuring a proportional relationship between the intensity of the symptoms and tobacco dependence ${ }^{[8]}$. In our study, there were no differences in intensity measured by the number of cigarettes per day or CO-oximetry between patients with and without psychiatric comorbidity. There were also no significant differences in the dependence measured by the Fagerström test or in the motivation measured by the Richmond. However, it is important to note that our patients were selected among those who only had completed the treatment, regardless of those who abandoned or even started it. A qualitative analysis of the causes of tobacco cessation and of the possible motivations to quit or continue smoking would also be interesting for a later work.

The average age of smoking onset in Castilla-La Mancha, according to the National Health Survey of the Ministry of Health and Social Affairs, is 17.2 years $^{[14]}$. This age coincides with the average age in Spain. The patients selected in our sample started smoking a little earlier at 16.7 years. It would be important, when trying to avoid smoking initiation, to do a qualitative analysis of the causes of onset, and possible differences between both populations.

In the developed world, half of those who request help to quit smoking have psychiatric comorbidity ${ }^{[7,8,15]}$. Among the patients in our sample, the prevalence was $37 \%$, which lies between the previous figure and the prevalence figures in the general population, which according to the studies is $17-20 \%{ }^{[16-18]}$.

The characteristics of the patients in our sample were similar between the patients with psychiatric comorbidity and those without, and there was only a difference in sex, where women had a higher psychiatric comorbidity frequency than men, which is similar to the frequency described in the general population ${ }^{[16,17]}$.

The systematic study that was performed, follow-up and treatment periods are those that are accepted in the guidelines ${ }^{[18]}$. Following the guidelines, important success levels have been achieved, with continuous abstinence rates per year between 27 and $33.7 \%^{[19,20]}$. There were no differences in treatment between the two groups, as the three types of pharmacological treatments (NRT, bupropion, and varenicline) were used in both groups. Despite the fact that at the time of the study there was still no scientific evidence regarding the use of varenicline, the publication of the EAGLES trial ${ }^{[21]}$, which demonstrates the safety of the three treatments in psychiatric patients, had already led to studies on the safety of varenicline.

The two groups behaved equally in terms of failure and relapse. There was no difference in the measurement of the target variable, that is, 'success'. The percentage of success in this study is between 63 and $74 \%$; however, these data are not comparable to the levels of abstinence that were reported in the previous paragraph, as our sample is different in the way that we selected the subgroup of patients treated at the Smoking Cessation Unit who 
completed the pharmacological treatment ${ }^{[22]}$. It is assumed that this group that did not abandon treatment would be especially motivated and predisposed. This is probably one of the major limitations of the study. Thus, it would be interesting to consider this study at different levels: all patients who request medical help to quit smoking, and differentiating patients do not start treatment and patient who start treatment.

Regarding the comparison between patients with and without psychiatric comorbidity distributed according to sex variable, there are no differences in treatment success, despite the higher frequency of psychiatric comorbidity in women.

\section{LIMITATIONS OF STUDY}

Selecting a time period instead of estimating a sample size based on the success rate is a limitation. The limitations inherent in record studies should also be considered.

\section{CONCLUSION}

Conventional smoking cessation treatment is effective in both populations. In addition, the characteristics of patients with psychiatric comorbidity who are able to complete pharmacological treatment do not differ in terms of intensity of smoking, degree of motivation, or dependence. Moreover, in female smokers, despite having more psychiatric morbidity, the treatment is equally effective.

\section{CONFLICT OF INTEREST}

There are no conflicts of interest.

\section{REFERENCES}

1. U.S. Department of Health and Human Services. Reducing the Health Consequences of Smoking: 25 Years of Progress. A Report of the Surgeon General. U.S. Department of Health and Human Services, Public Health Service, Centers for Disease Control, Center for Chronic Disease Prevention and Health Promotion, Office on Smoking and Health. DHHS Publication No. (CDC) 89-8411. 1989. Available at https://profiles.nlm.nih.gov/ps/access/NNBBXS.pdf

2. The health consequences of smoking: a report of the Surgeon General. [Atlanta, Ga.]: Dept. of Health and Human Services, Centers for Disease Control and Prevention, National Center for Chronic Disease Prevention and Health Promotion, Office on Smoking and Health; Washington, DC: U.S. G.P.O., 2004. Available at: http//www.cdc.gov/tobacco/ data_statistics/sgr/2004/pdfs/executiv esummary.pdf. [Accessed 10 August 2015].

3. The World Health Organization. The ICD-10 classification of mental and behavioural disorders: clinical descriptions and diagnostic guidelines. Geneva: World Health Organization; 1992.

4. WHO. International Classification of Diseases (ICD). Available at: http:/www.who.int/classifications/icd/ en/. [Accessed 7 July 2015].

5. De Granda Orive JI. Smoking as a chronic addictive disease. In: Jiménez-Ruiz CAY, Fagerström KO, editors. Treaty of Smoking. 2nd ed. Madrid: Ergon; 2007. pp. 99-119.

6. American Psychiatric Association. Diagnostic and Statistical Manual Of Mental disorders. 5th ed. Washington, DC: American Psychiatric Association; 2013.

7. Lasser K, Boyd W, Woolhandler S, Himmelstein DU, McCormick D, Bor DH. Smoking and mental illness: a population based prevalence study. JAMA 2000; 284:2606-2610.

8. Serebrisky D. Smoking in psychiatric patients. In: Serebrisky D, Müller FW, editors. Smoking and psychiatric disease. Tools for action. 1st ed. Argentina: Science; 2012. pp. 67-80.

9. Higes Martinez EB, Ramos Pinedo A, Nistal Rodriguez A. Comprehensive treatment of smoking. In: Higes Martínez EB, Perera López L, editors. Management of diagnosis and treatment of smoking in daily clinical practice: SEPAR Procedures Manual 32. Spain: Respira-Fundación Española Del PulmónSEPAR; 2015, pp. 30-41.

10. Agency for the Evaluation of Sanitary Technologies Evaluation of the efficacy, effectiveness and costeffectiveness of the different therapeutic approaches to quit smoking. Madrid: AETS of the Carlos III Health Institute; 2003.

11. Shiffman S, Ferguson SG. Nicotine patch therapy prior to quitting smoking: a meta-analysis. Addiction 2008; 103:557-563.

12. Hays JT, Hurt RD, Rigotti NA, Niaura R, Gonzales $\mathrm{D}$, Durcan MJ, et al. Sustained-released bupropion form pharmacologic relapse prevention after smoking cessation: a randomized, controlled trial. Ann Intern Med 2001; 135:423-433.

13. Hays T, Ebbert J. Adverse effects and tolerability of medications for the treatment of tobacco use 
dependence. Drugs 2010; 70:2557-2572.

14. Ministry of Health, Social Services and Equality. Statistical Portal of the NHS [Intrenet]. National Health Survey of Spain 2011/2012. Available at: http://www.msssi.gob.es/estadEstudios/estadisticas/ encuestaNacional/encuesta2011.htm. [Accessed 9 August 2015].

15. Ziedonis D, Williams JM, Smelson D. Serious mental illness and tobacco addiction: a model program to address this common but neglected issue. Am J Med Sci 2003; 326:223-230.

16. Rajmil L, Gispert Magarolas R, Roset Gamisans M, Muñoz Rodríguez PE, Segura Benedicto A. Team of the Catalan Health Survey. Prevalence of mental disorders in the general population of Catalonia. Gac Sanit 1998; 12:153-159.

17. Haro JM, Palacín C, Vilagut G, Martínez M, Bernal $\mathrm{M}$, Luque I, et al. Prevalence of mental disorders and associated factors: results of the ESEMeD-Spain study. Med Clin (Barc) 2006; 126:445-445.

18. Rábade Castedo C, Lama López A, Dablanca Pallares M. Diagnostic approach of the smoker patient. In: Higes Martínez EB, Perera López L, editors. Management of diagnosis and treatment of smoking in daily clinical practice: SEPAR Procedures Manual 32. Spain: Respira-Fundación Española Del PulmónSEPAR; 2015, pp. 9-29.

19. Godoy Mayoral R, Genovés Crespo M, Callejas González FJ, Tornero Molina AI, Tárraga López PJ, Rodríguez Montes JA. Abstinence at 3, 6, 9 and 12 months in the specialized consultation of smoking cessation of the University Hospital Complex of Albacete. Prev Tab 2016; 18:71-77.

20. Callejas González FJ, Genovés Crespo M, Cruz Ruiz J, Tornero Molina AI, Esquinas López C, Bermejo López $\mathrm{P}$, et al. Continuous abstinence rates at 3, 6, 9 and 12 months in a Smoking Cessation Unit at the Albacete University Hospital over 2 years. Int J Respir Pulm Med 2015; 2:1.

21. Anthenelli RM, Benowitz NL, West RSt, Aubin L, McRae T, Lawrence D, et al. Neuropsychiatric safety and efficacy of varenicline, bupropion, and nicotine patch in smokers with and without psychiatric disorders (EAGLES): a double-blind, randomised, placebocontrolled clinical trial. Lancet 2016; 387:2507-2520.

22. Garza D, Murphy M, Tseng LJ, Riordan HJ, Chatterjee A. A double-blind randomized placebo-controlled pilot study of neuropsychiatric adverse events in abstinent smokers treated with varenicline or placebo. Biol Psychiatry 2011; 69:1075-1082. 